\title{
Smiling to Smiles After Exclusion: Social Rejection Enhances Affiliative Signalling
}

\section{Dr Michael Philipp}

School of Psychology

m.philipp@massey.ac.nz 


\section{Exclusion}

How does social exclusion recalibrate social cognition? 


\section{Exclusion}

Social

Monitor

Pickett, Gardner, \& Knowles, 2005 


\section{Exclusion}

Social Monitor 


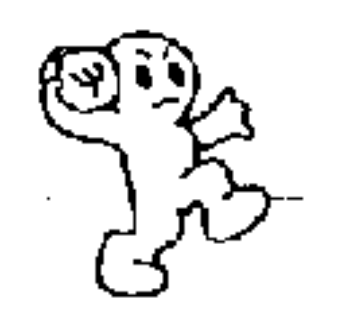

\section{${ }^{2} \mathbb{R}^{2}$}

sis

Excluded people mimic the behaviours of others more.

Lakin, Chartrand, \& Arkin (2008) 


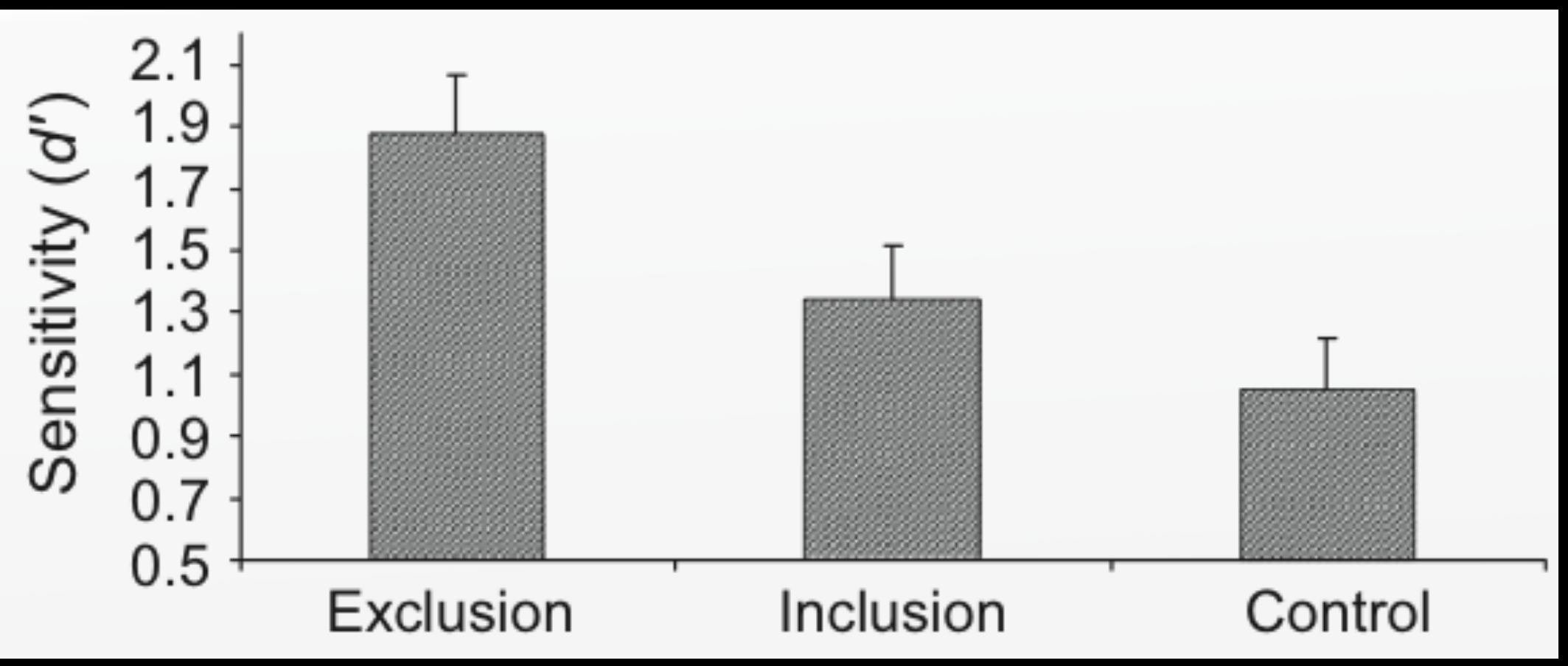

Social exclusion enhances the ability to differentiate genuine and posed smiles.

Bernstein et al., 2008 


\section{Duchenne Smile}

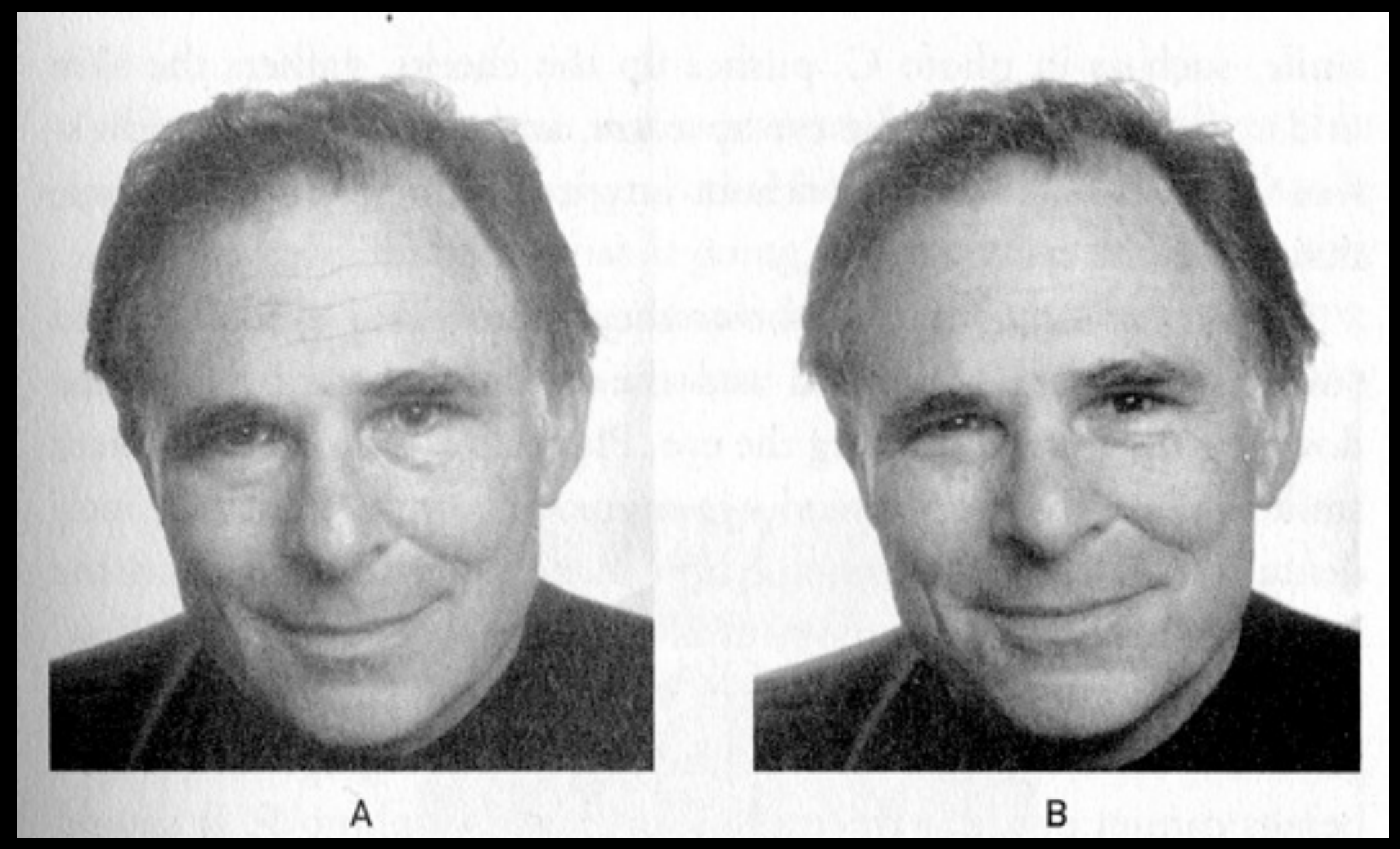

Posed

Genuine 


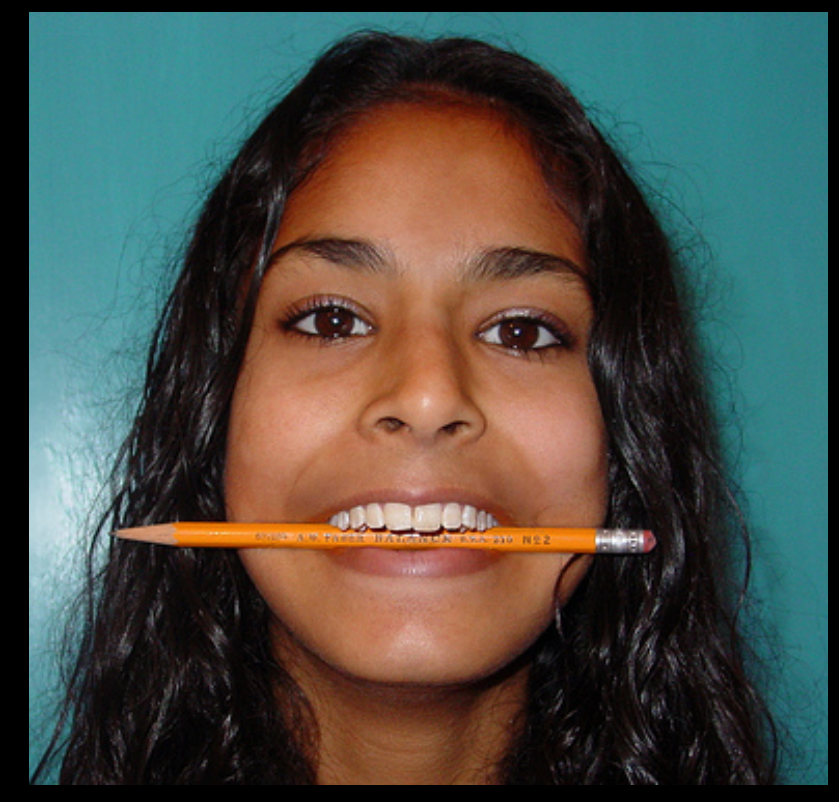

Blocking facial mimicry can inhibit recognition of happy expressions. 


\section{a model}

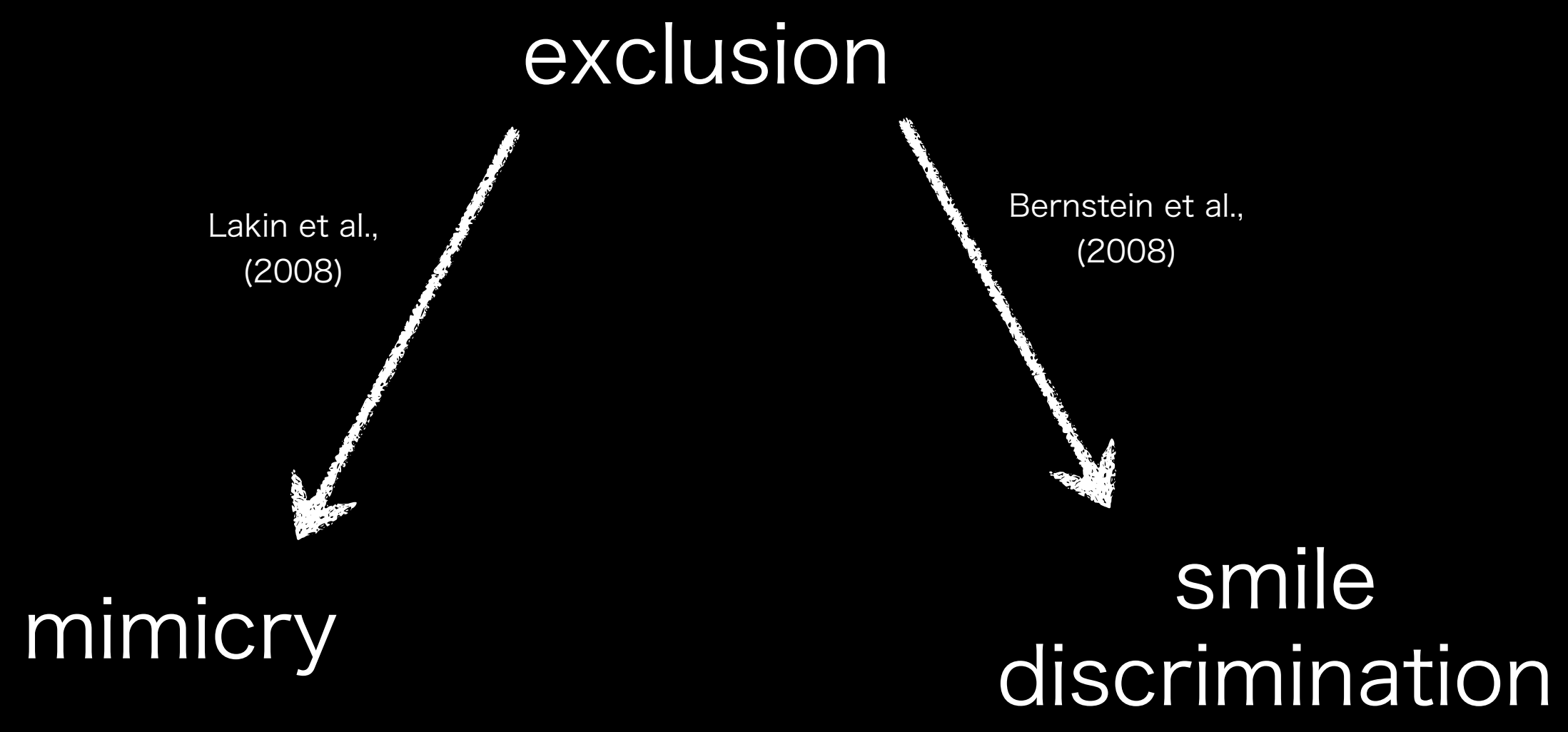




\section{a model}

\section{exclusion}
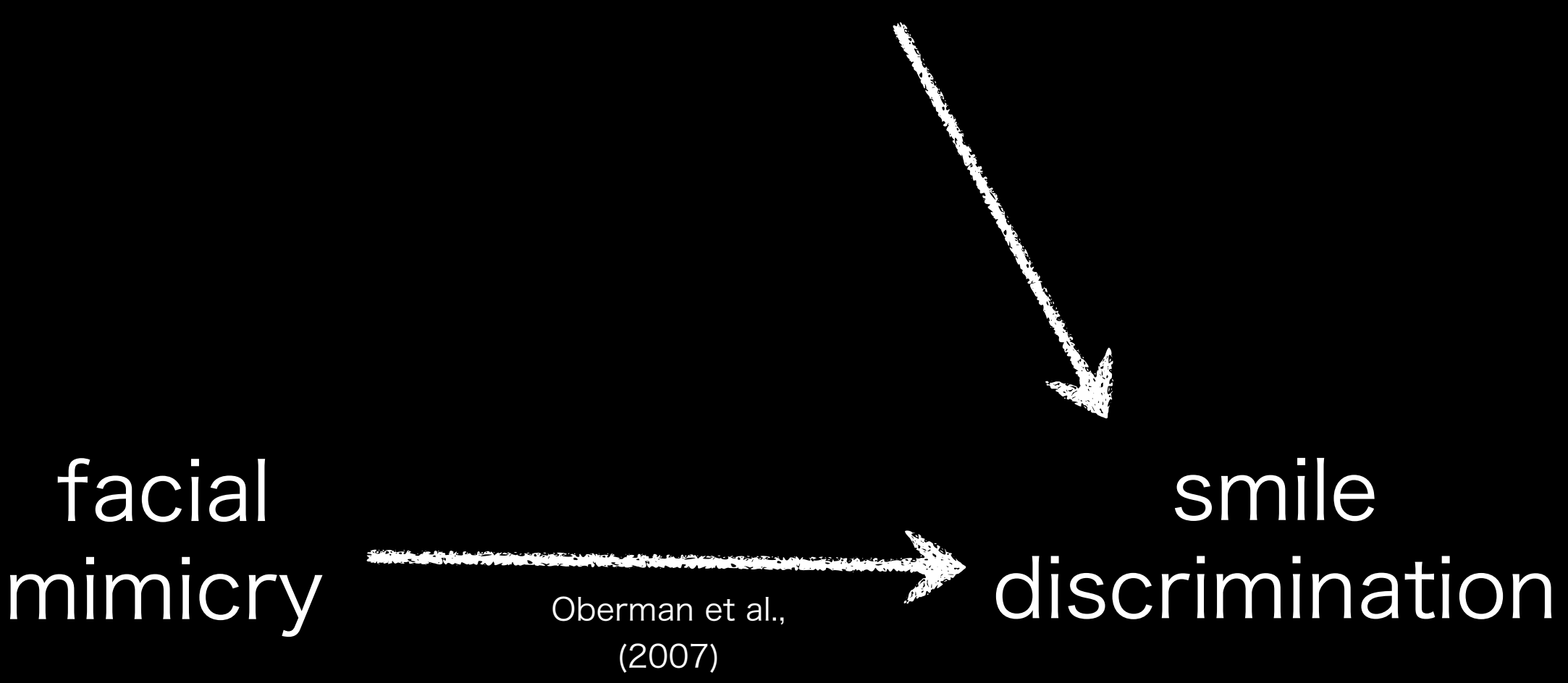
a model

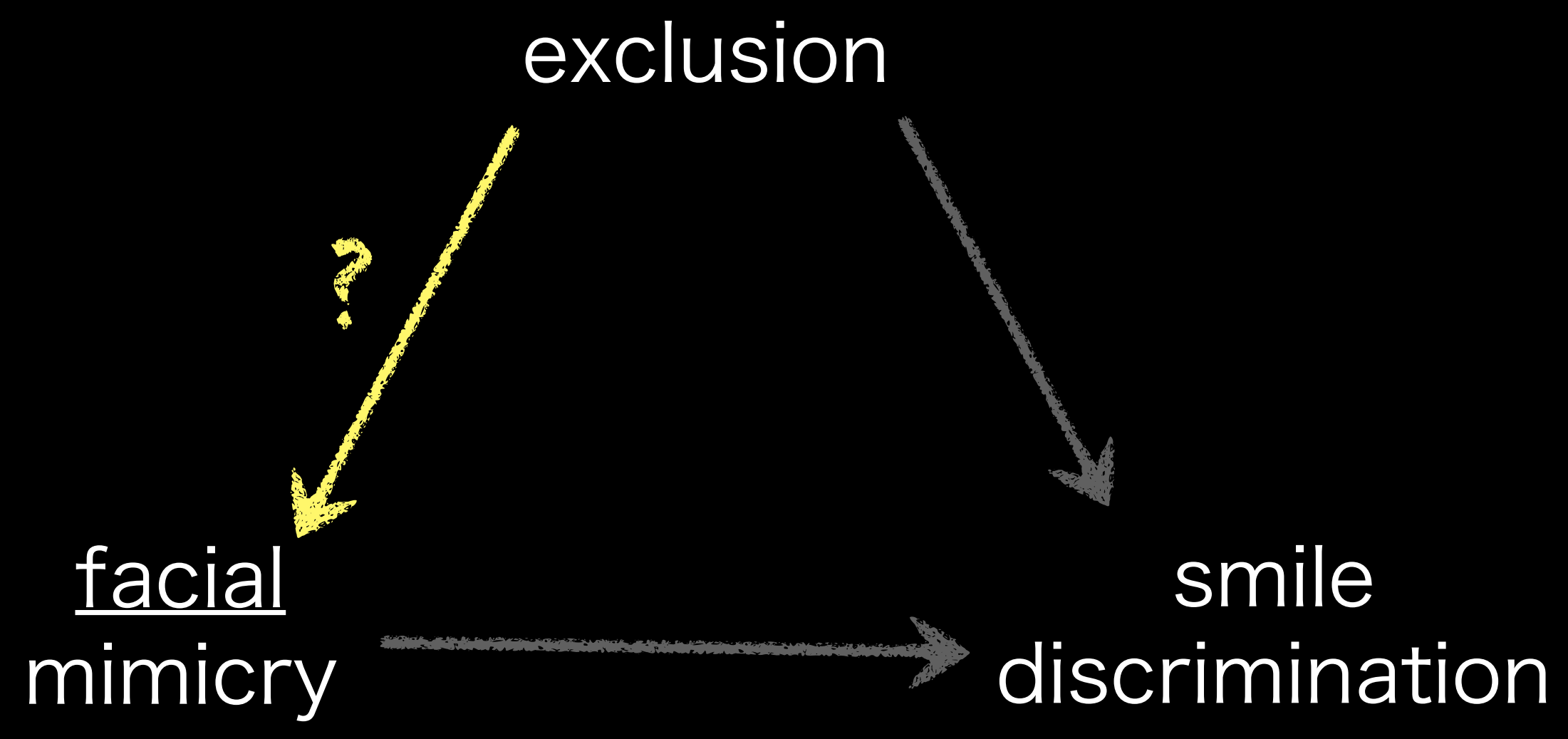




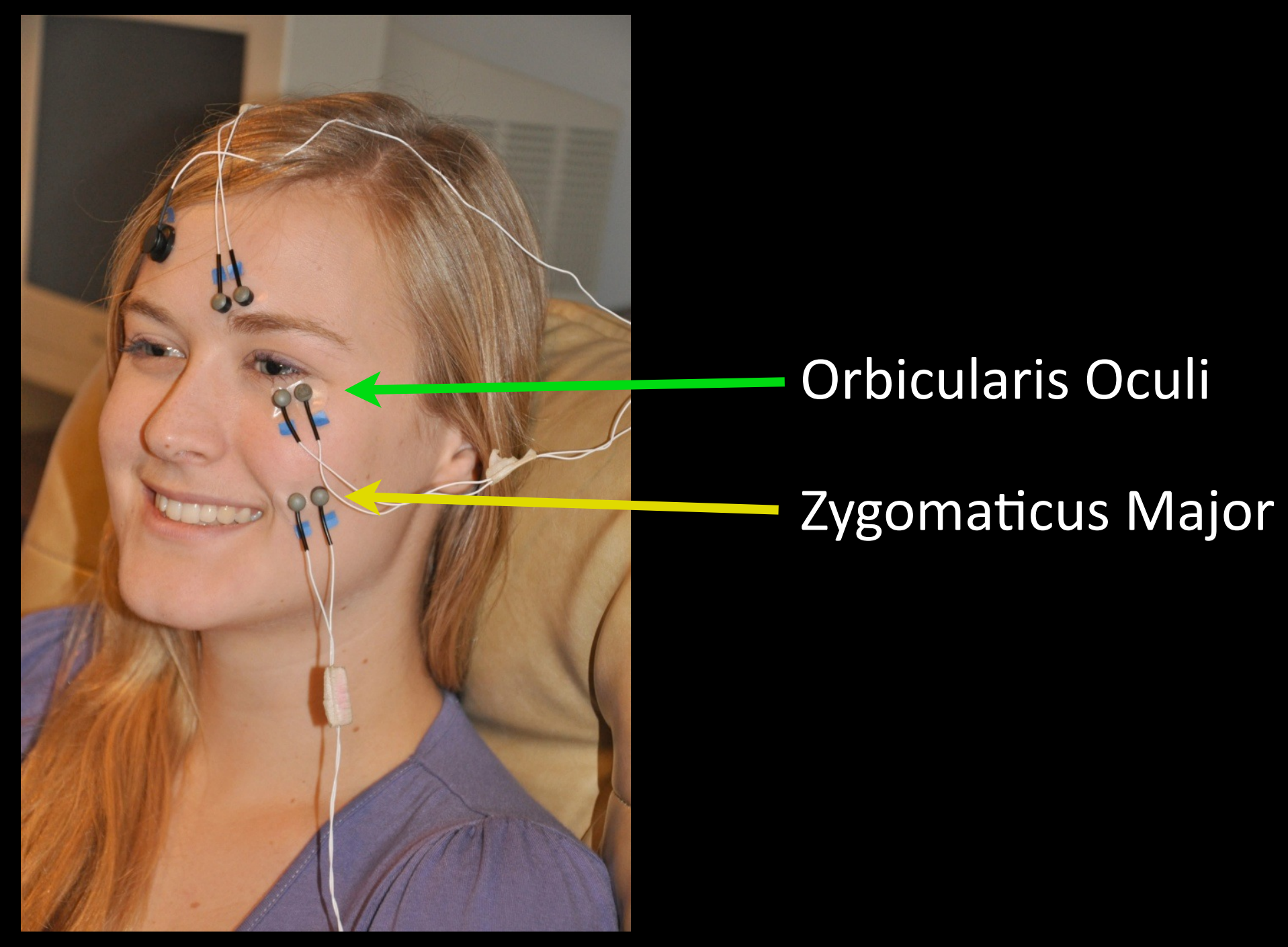




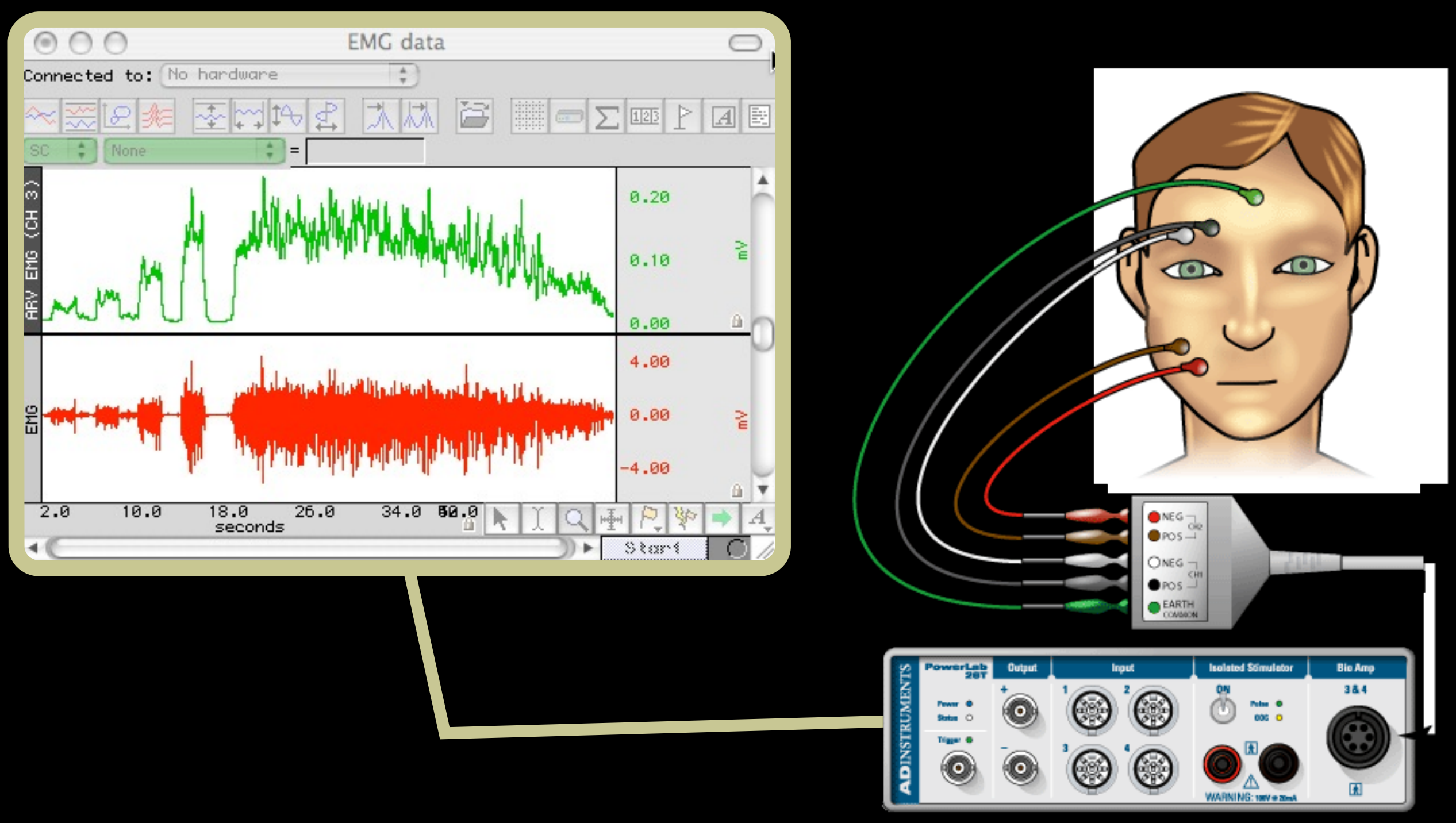




\section{Exclusion induction}

Write about a time you were rejected or excluded.

\section{method \\ sos 203}

Write about waking up yesterday morning. 
1. Exclusion induction

2. viewed 26 smiles (13 genuine, 13 posed)

\section{method}




\section{Exclusion induction}

2. viewed 26 smiles (13 genuine, 13 posed)

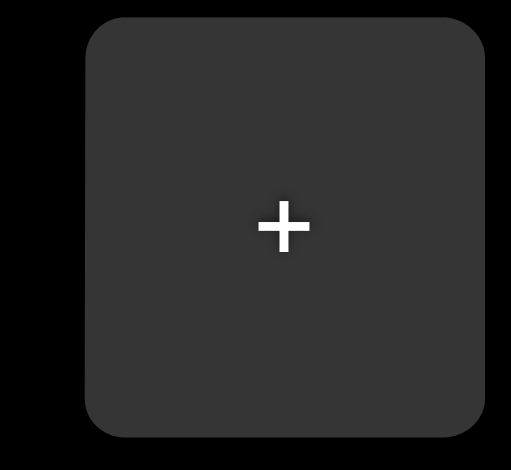

fixation

$\sim 5000 \mathrm{~ms}$

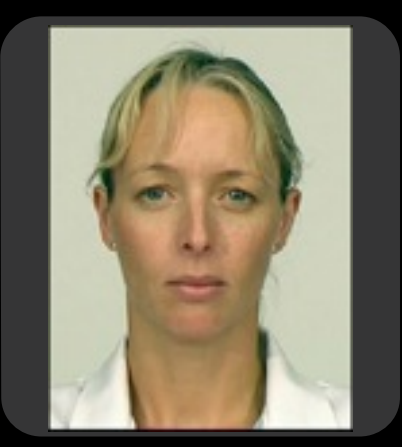

neutral $1500 \mathrm{~ms}$

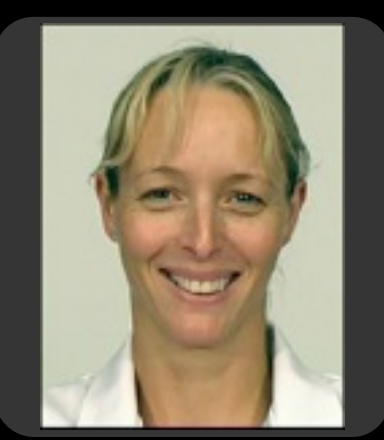

smile $1000 \mathrm{~ms}$

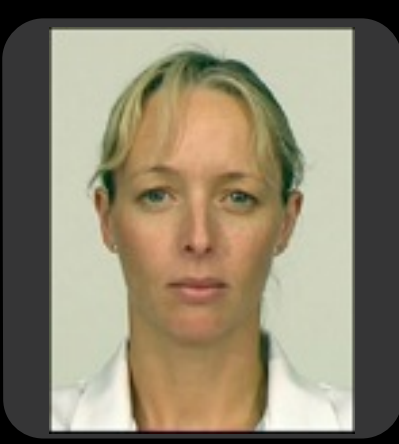

neutral $4500 \mathrm{~ms}$

\section{method}



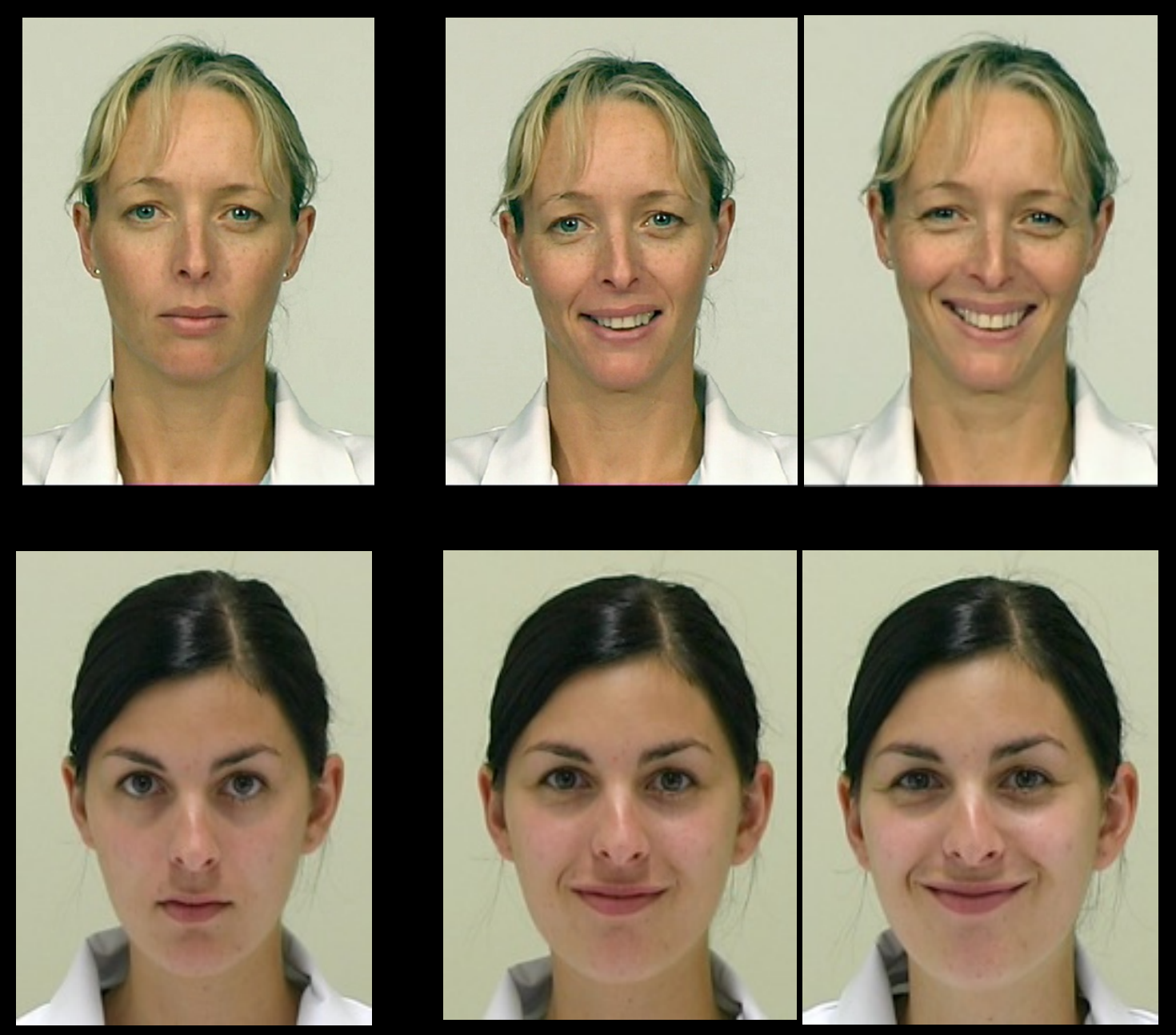

\section{3 people, 3 expressions each}

\section{stimuli}

Johnston, L., Miles, L, \& Macrae, C. (2010). Why are you smiling at me? Social functions of enjoyment and non-enjoyment smiles. British Journal of Social Psychology, 49, 107-127. 
1. Exclusion induction

2. viewed 26 smiles (13 genuine, 13 posed)

3. participants judged each smile as genuine or posed

\section{method}




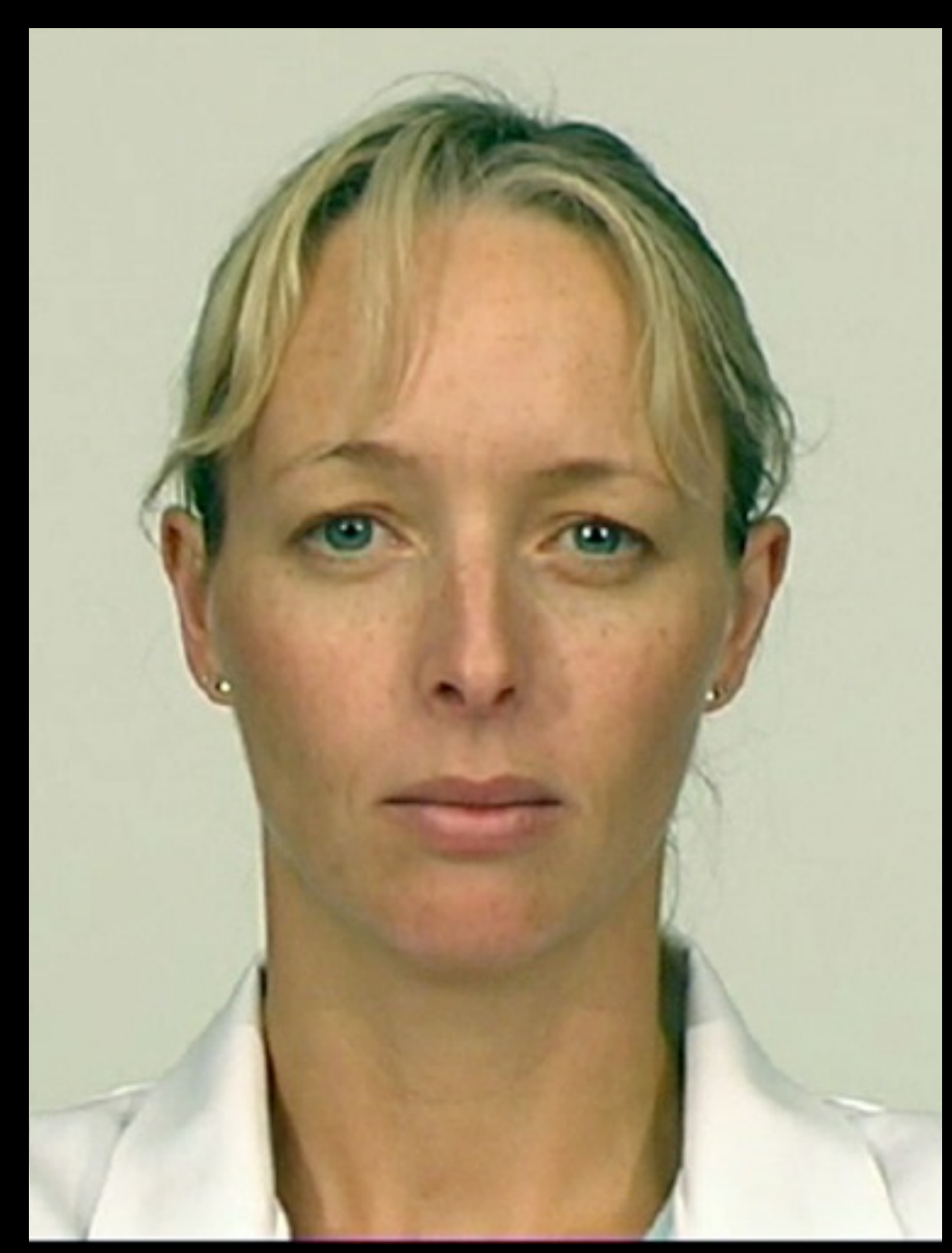




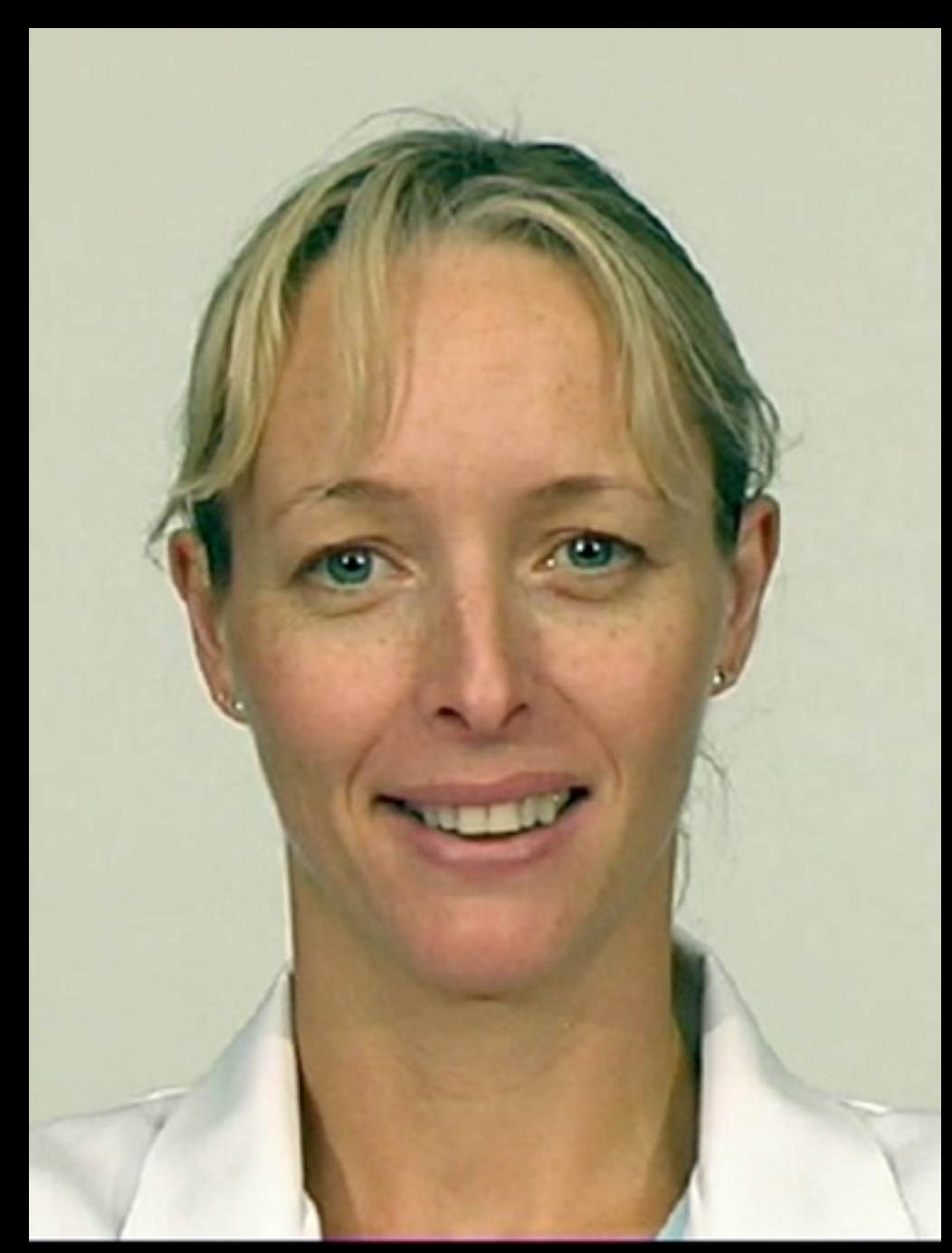




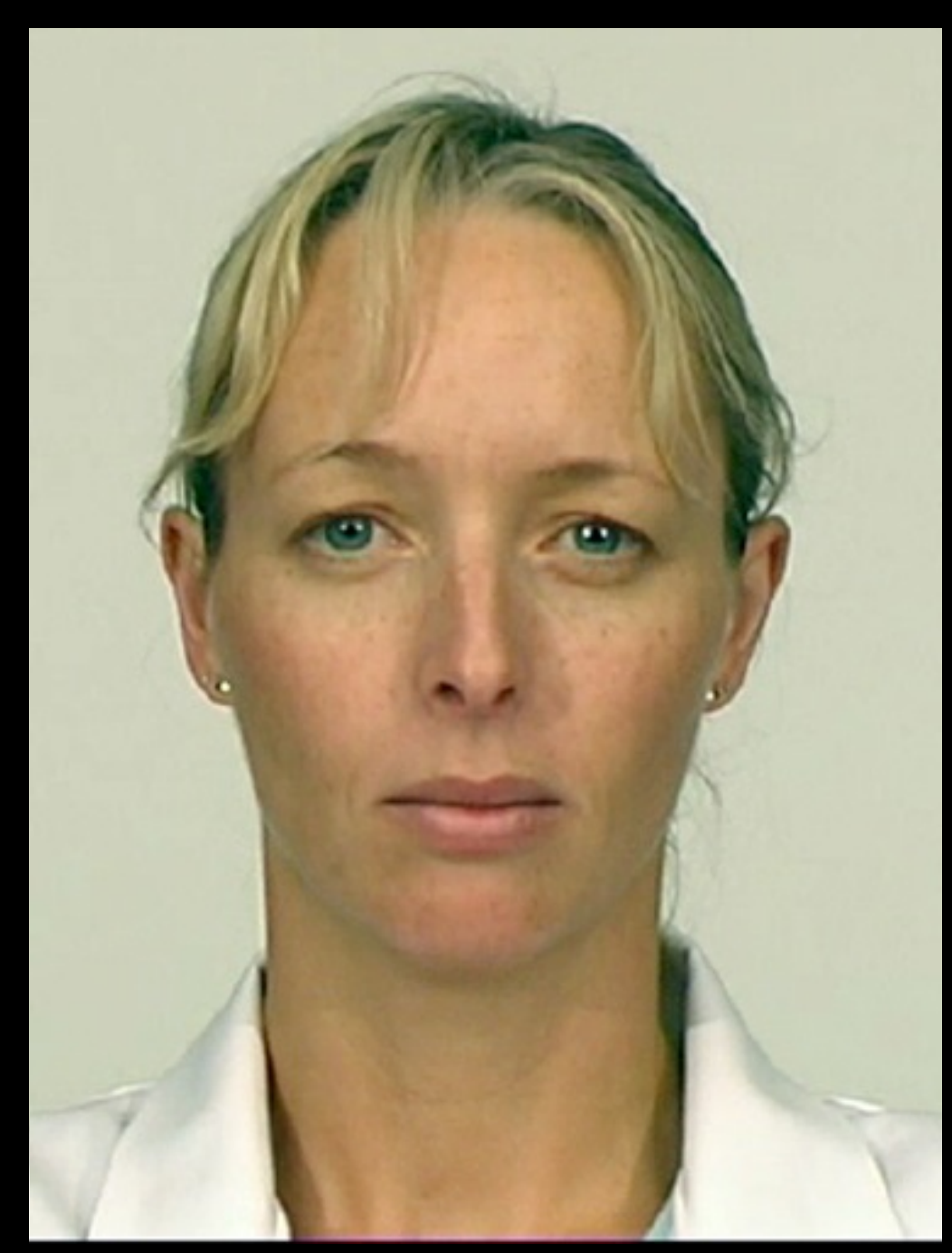


Real or Posed? 


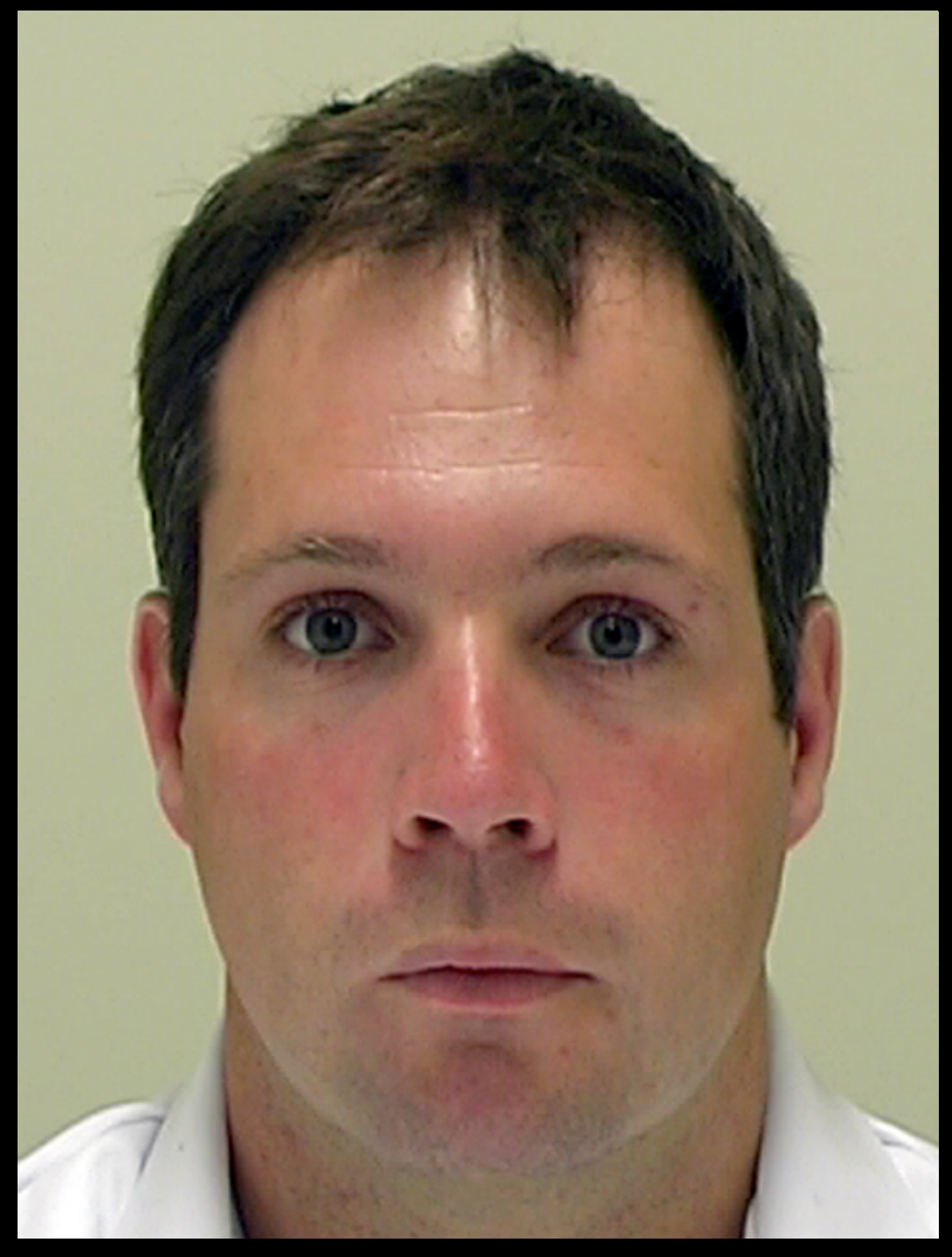




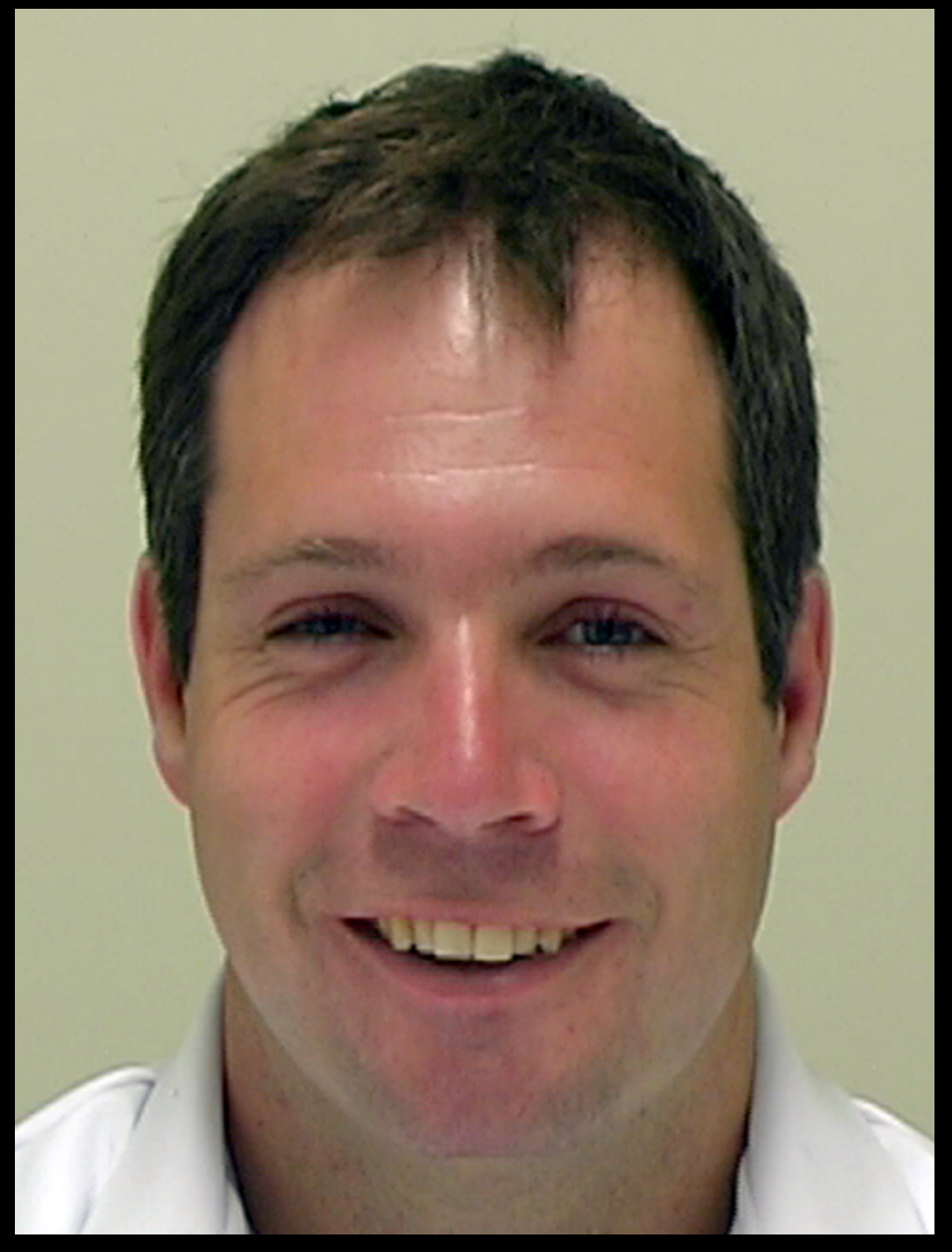




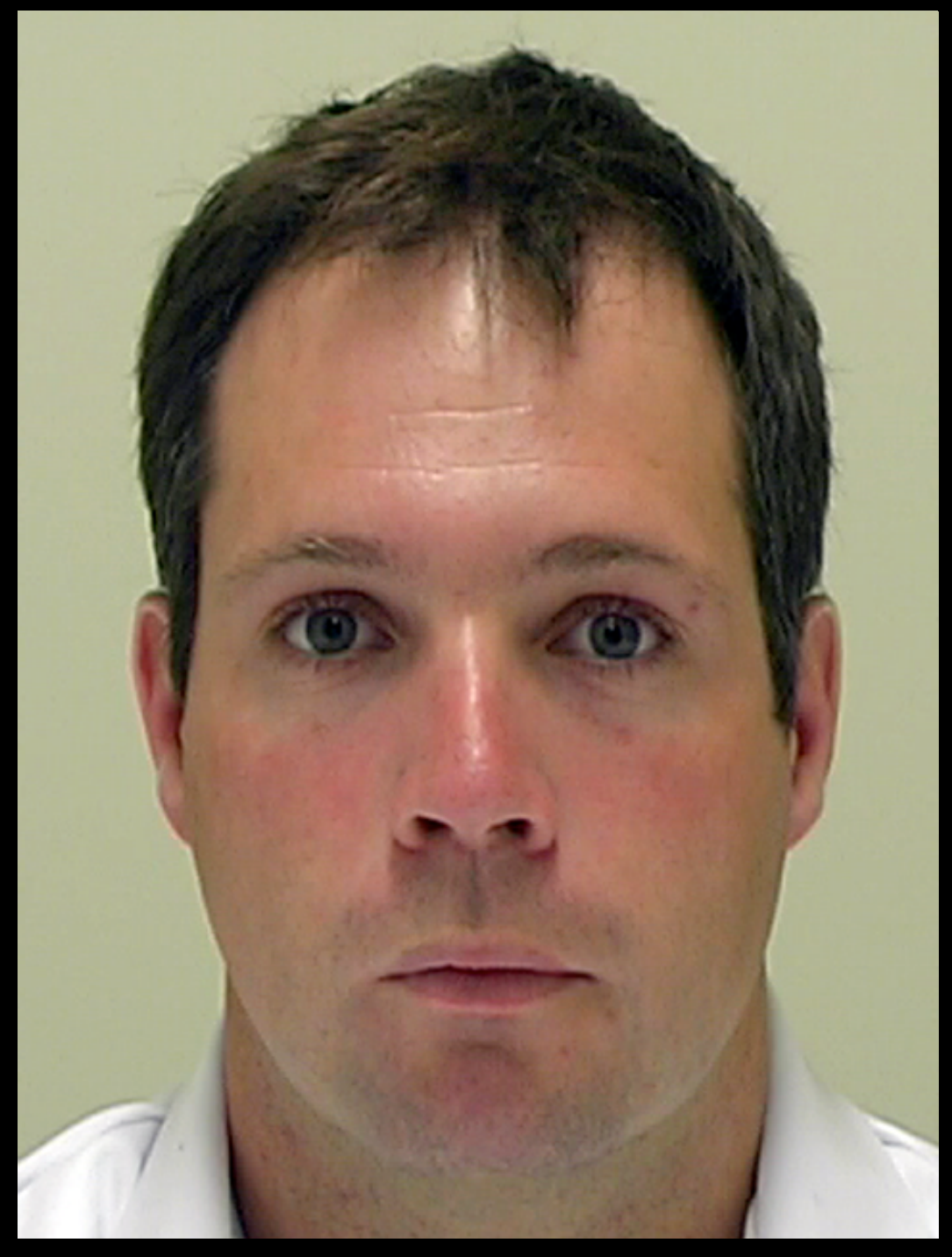


Real or Posed? 


\section{Results:}

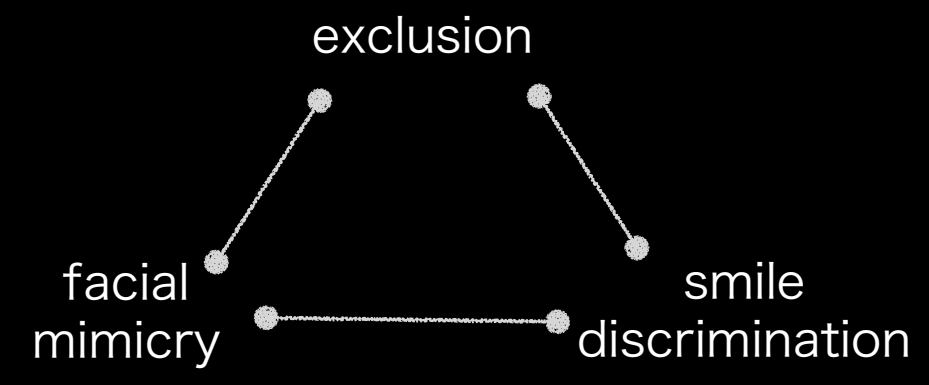




\section{Results:}

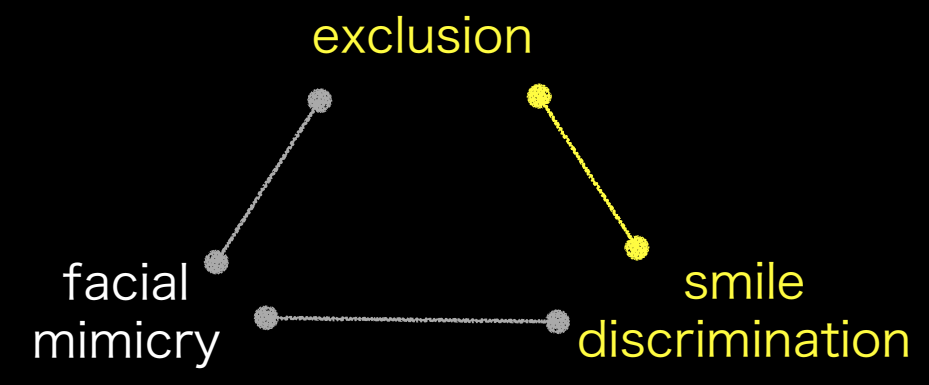




\section{Results:}

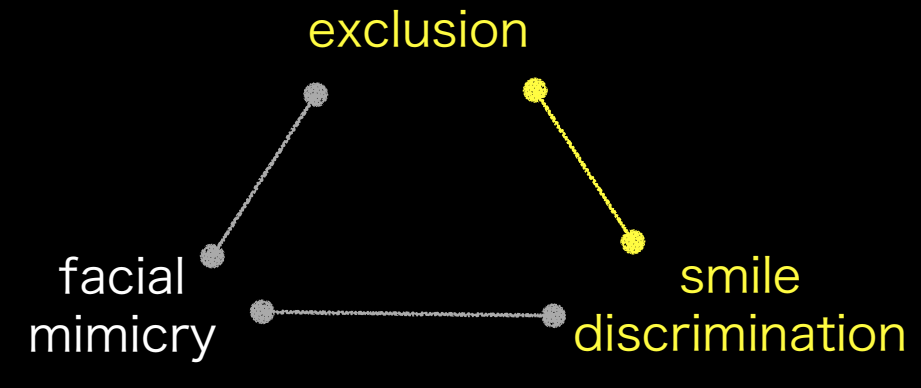

Ability to discriminate genuine smiles

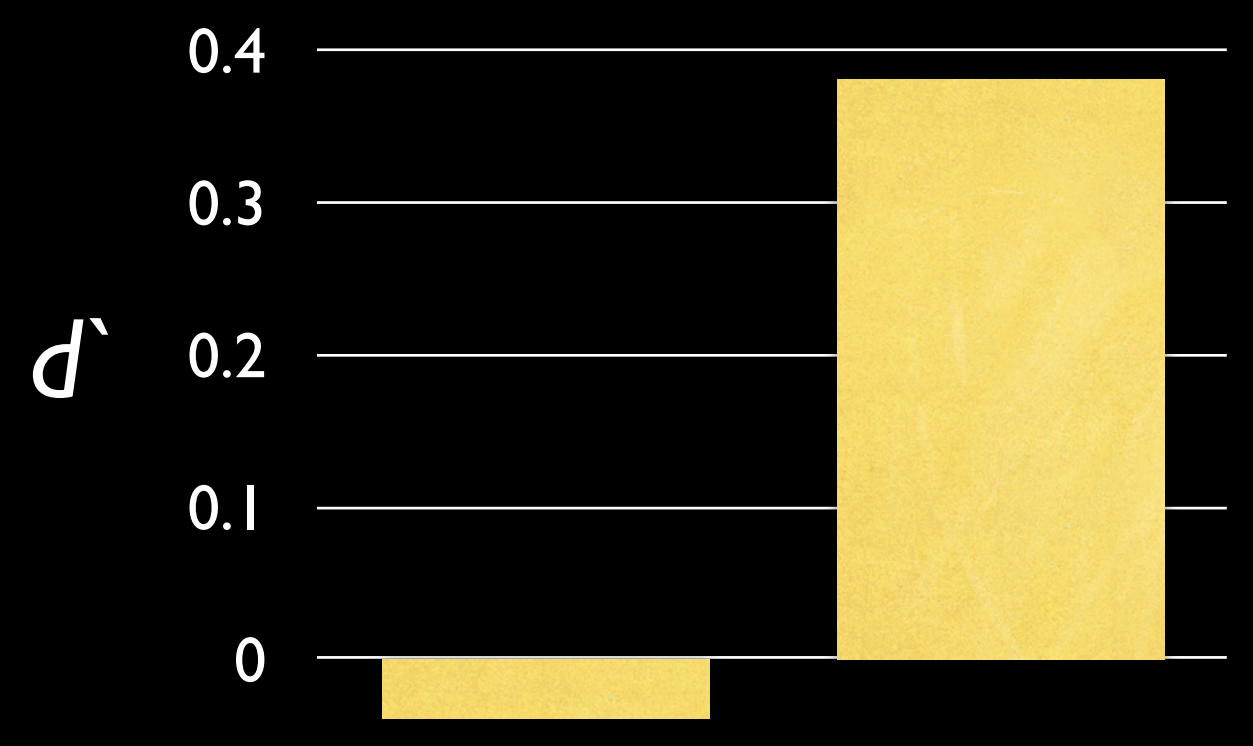

$-0.1$ 
Facial muscle activity

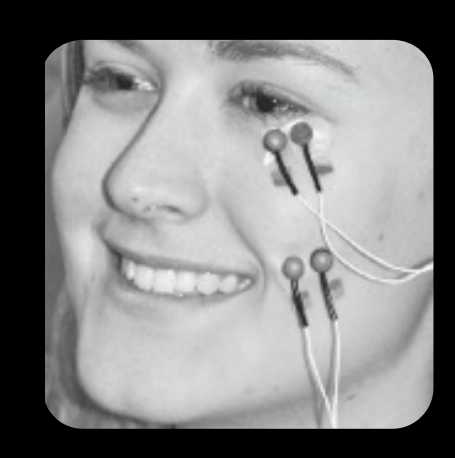

\section{results}




\section{Facial muscle activity}

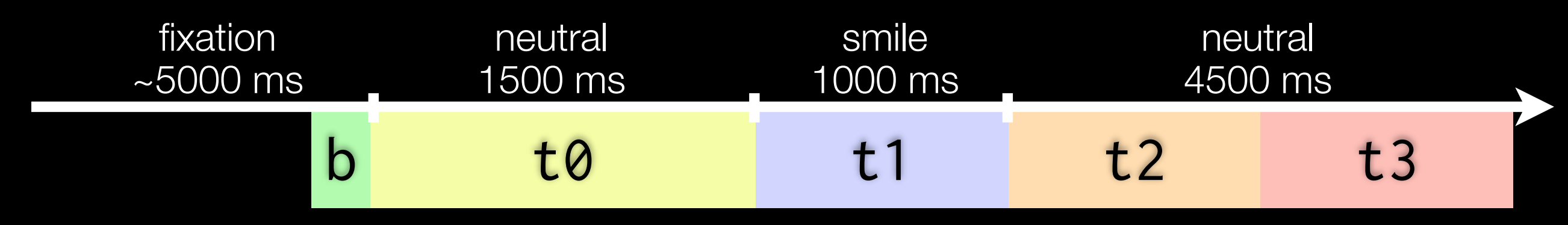

\section{results}




\section{Results:}

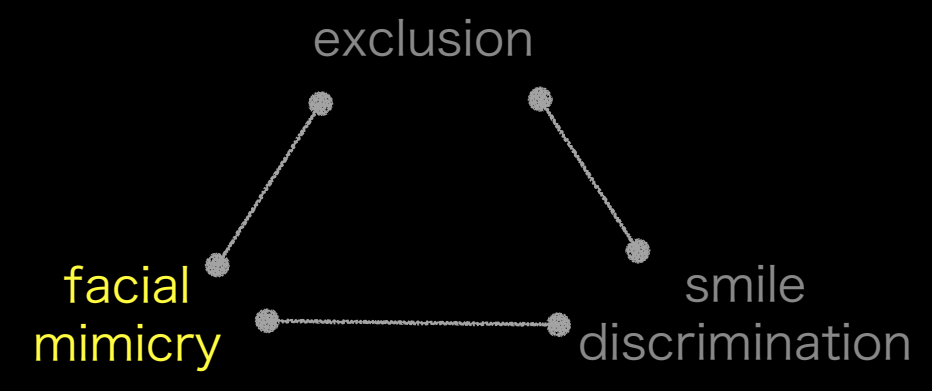

Are genuine and posed smiles differently mimicked? 


\section{Results:}

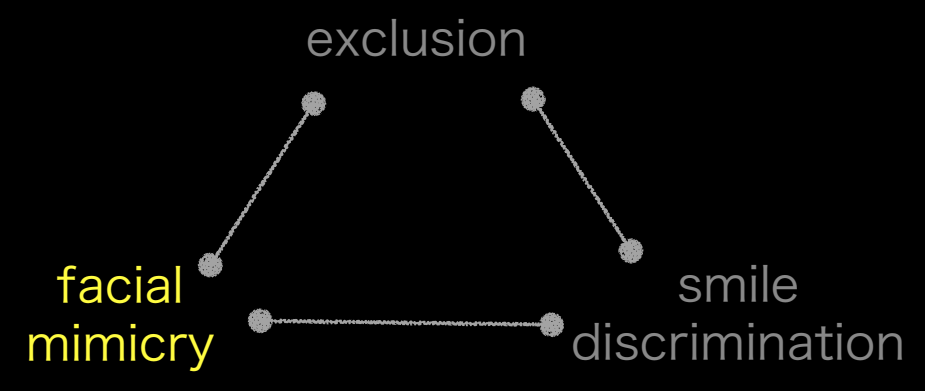

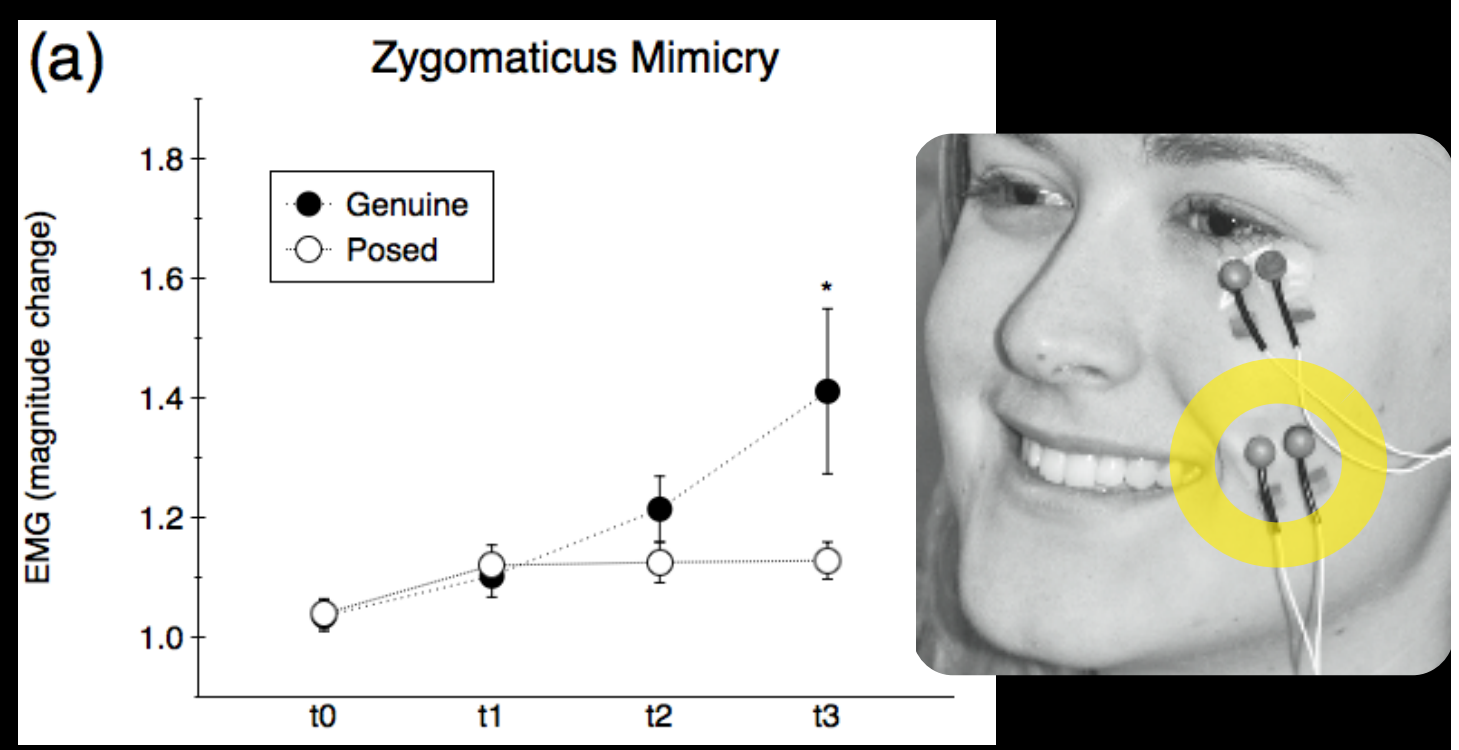

\section{Are genuine and posed smiles differently mimicked?}

Mean EMG activity for all participants in response to genuine and posed smiles. All $\mathrm{t} 1, \mathrm{t} 2$, and $\mathrm{t} 3$ data points differ from the respective treatment's $\mathrm{t} 0$ data point at $p<.05$. (a) Pairwise comparisons between treatment conditions revealed Genuine smile evoked greater zygomaticus activity at t3 $(* p<.05)$. 


\section{Results:}

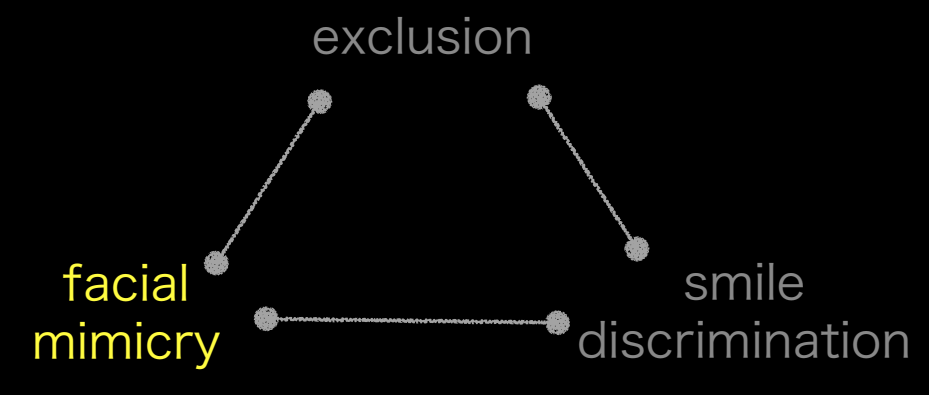

Are genuine and posed smiles differently mimicked?

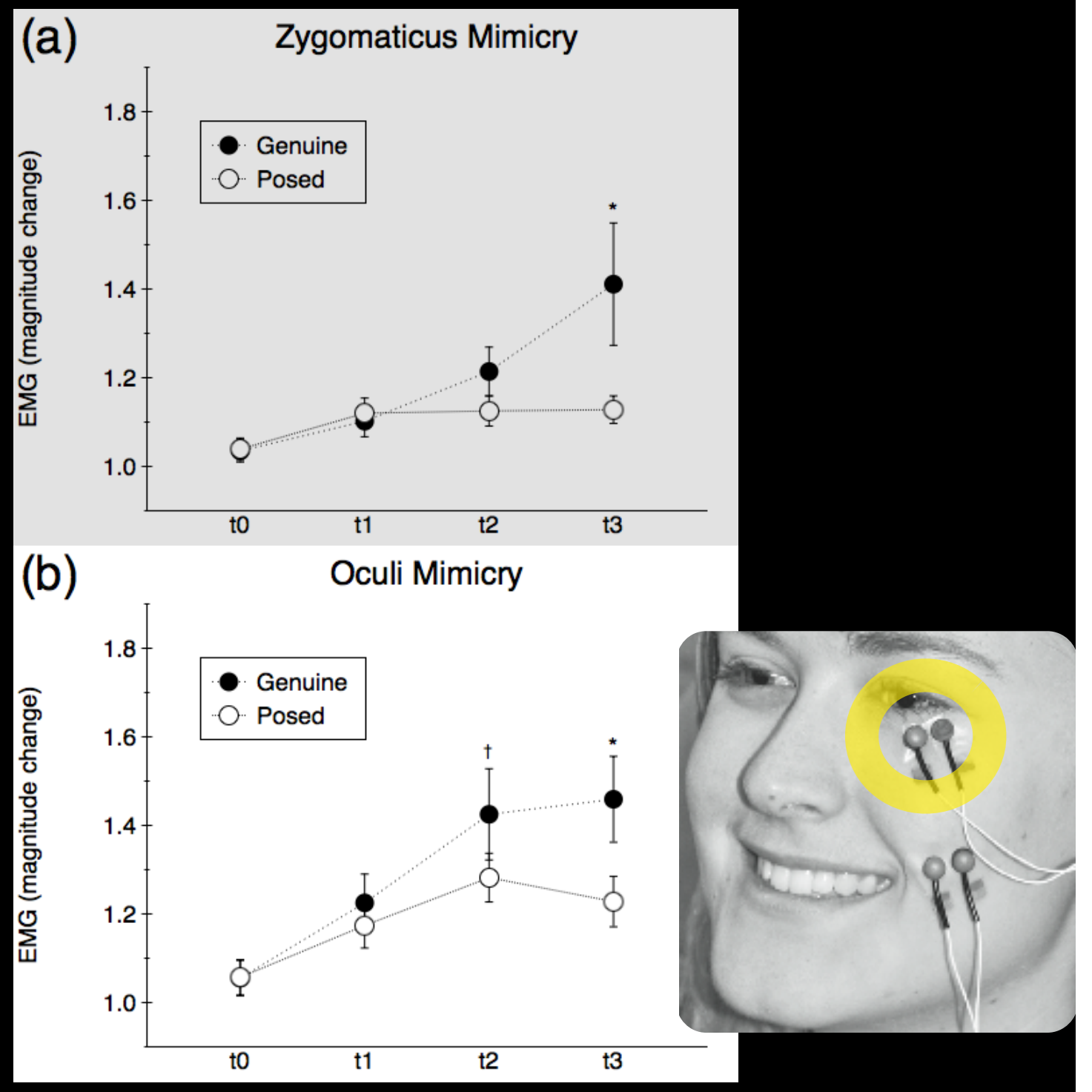

Mean EMG activity for all participants in response to genuine and posed smiles. All $\mathrm{t} 1, \mathrm{t} 2$, and $\mathrm{t} 3$ data points differ from the respective treatment's $\mathrm{t} 0$ data point at $p<.05$. (a) Pairwise comparisons between treatment conditions revealed Genuine smile evoked greater zygomaticus activity at t3 $\left({ }^{*} p<.05\right)$. (b) Pairwise comparisons between treatment conditions revealed Genuine smile evoked greater oculi activity at $\mathrm{t} 2(\dagger p<.10)$ and at t3 $(* p<.05)$. Note: Error bars represent \pm 1 SEM. 


\section{Results:}

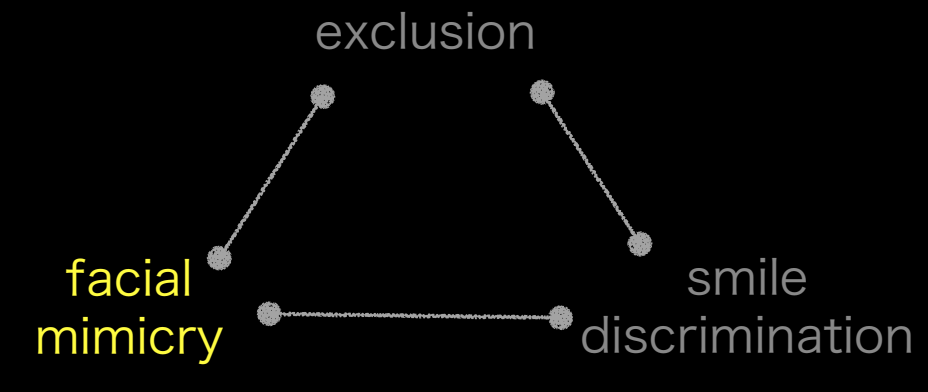

Are genuine and posed smiles differently mimicked?

Seems like it.
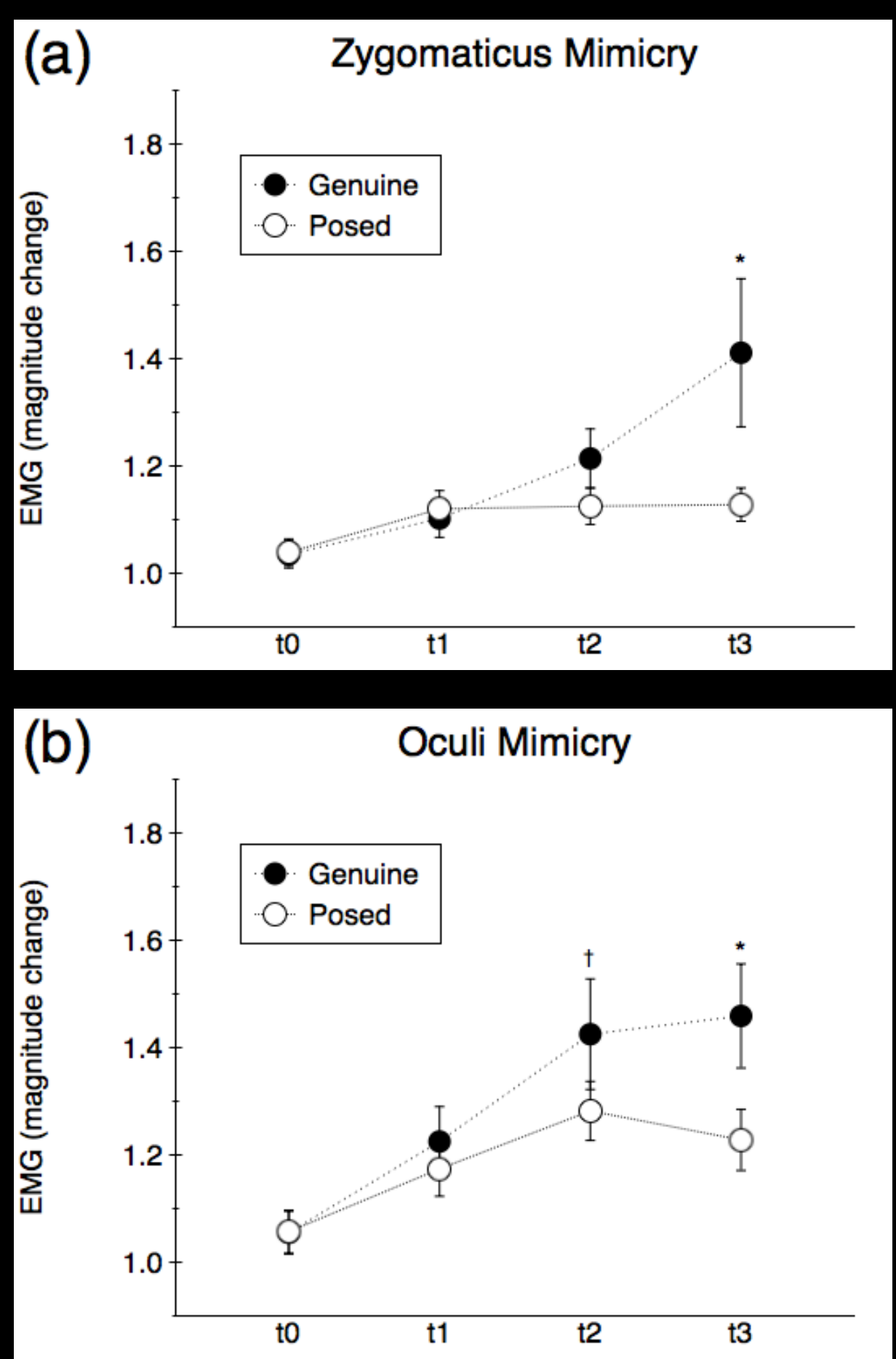


\section{Results:}

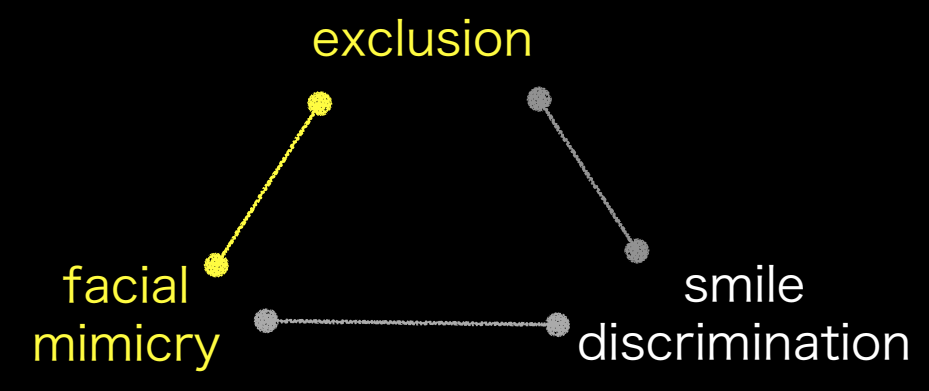

Does social

exclusion affect facial mimicry? 


\section{Results:}
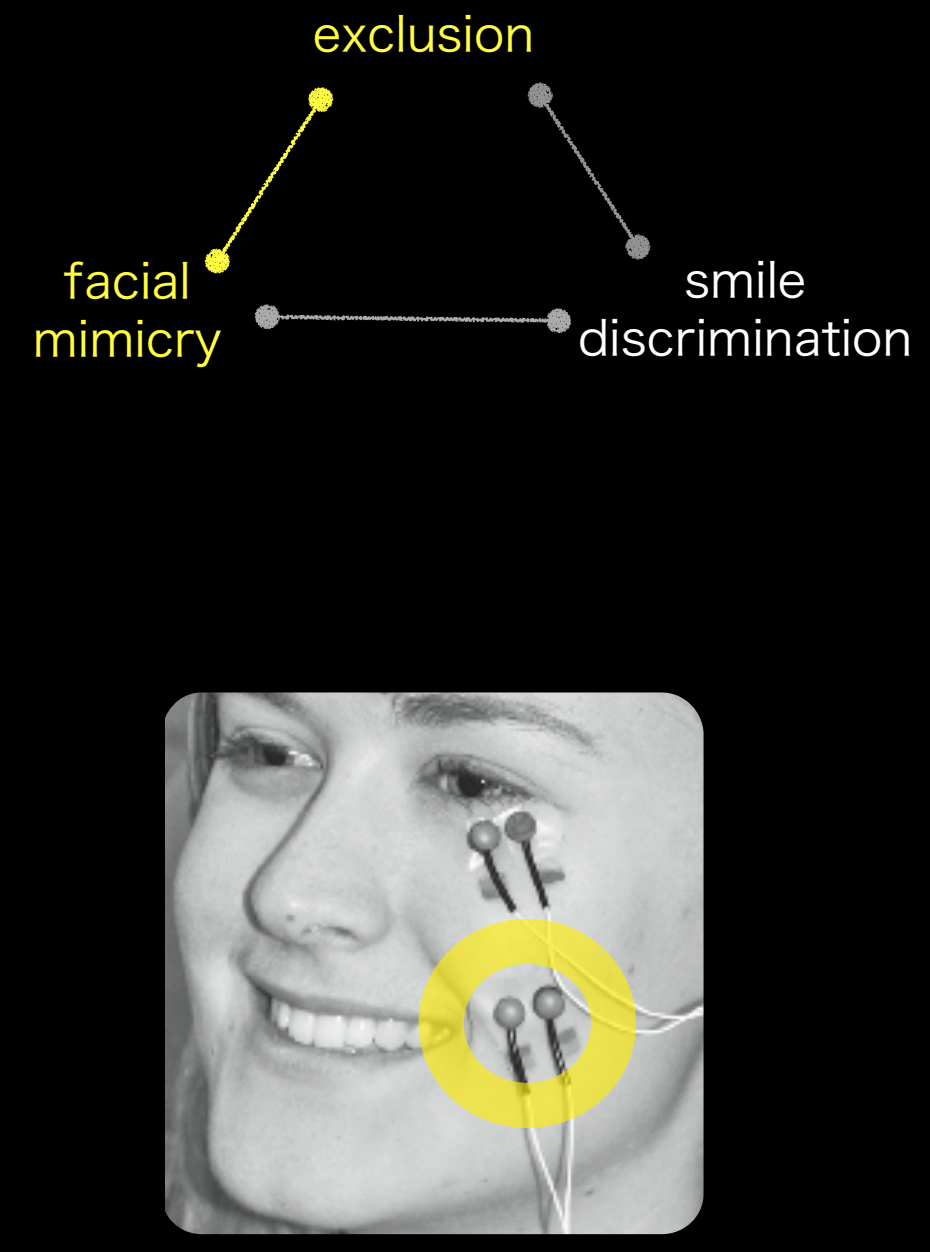


\section{Results:}
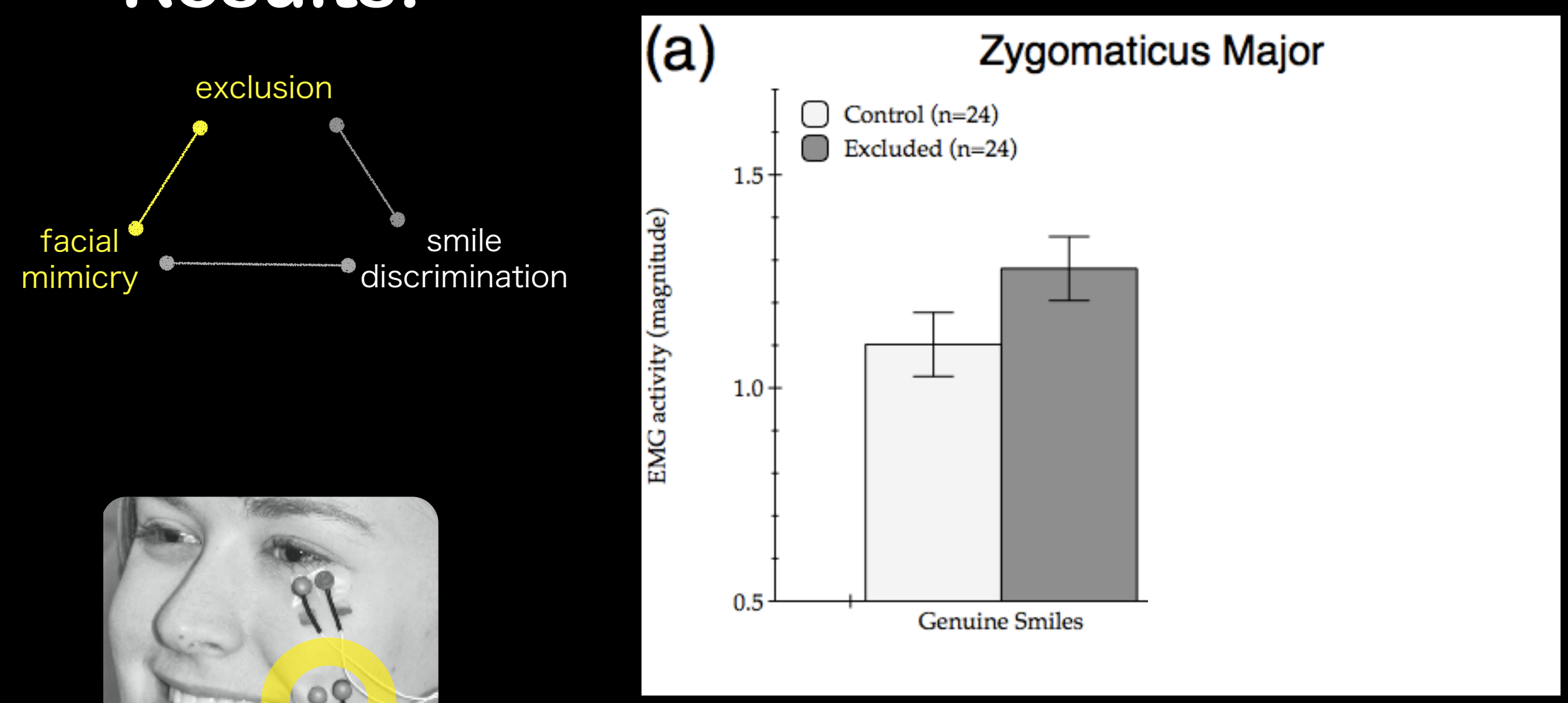


\section{Results:}
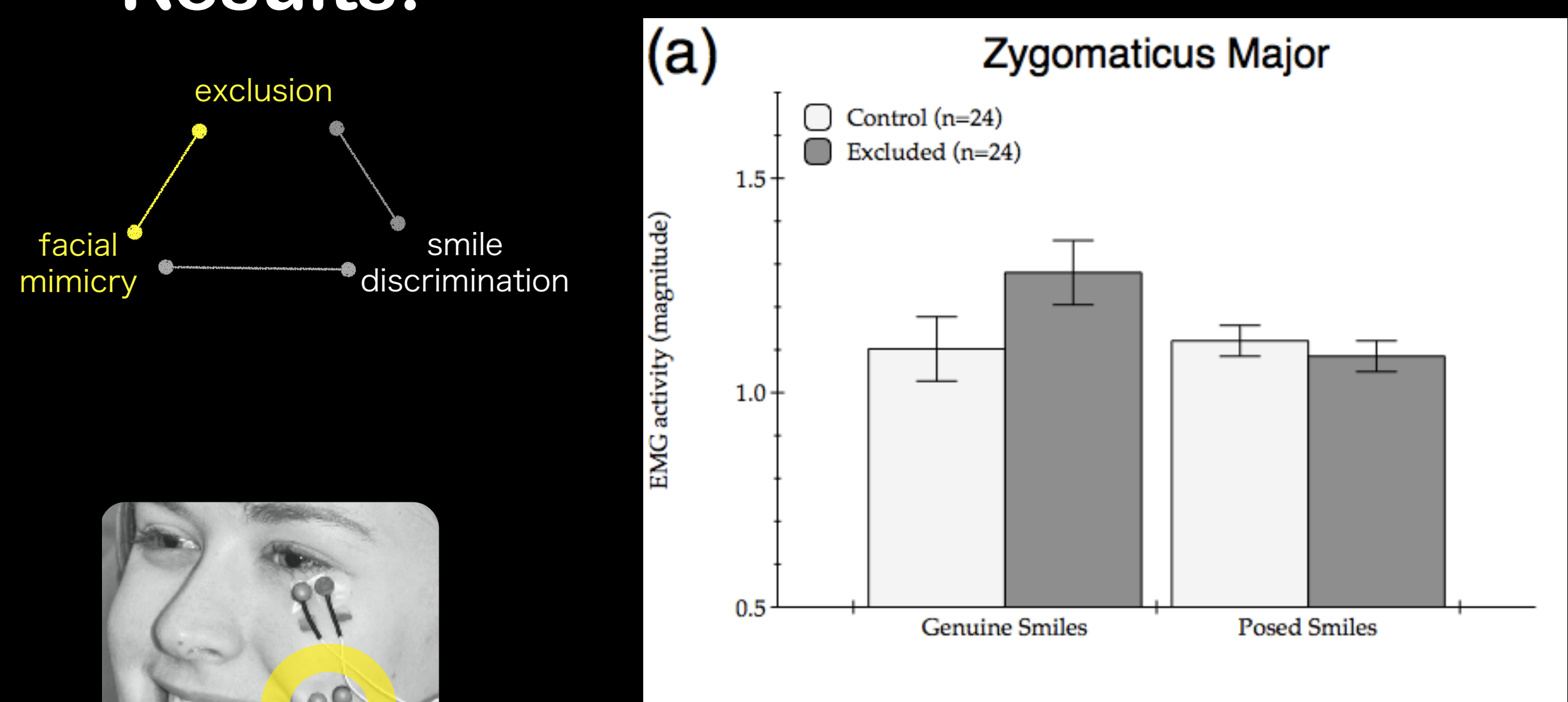


\section{Results:}
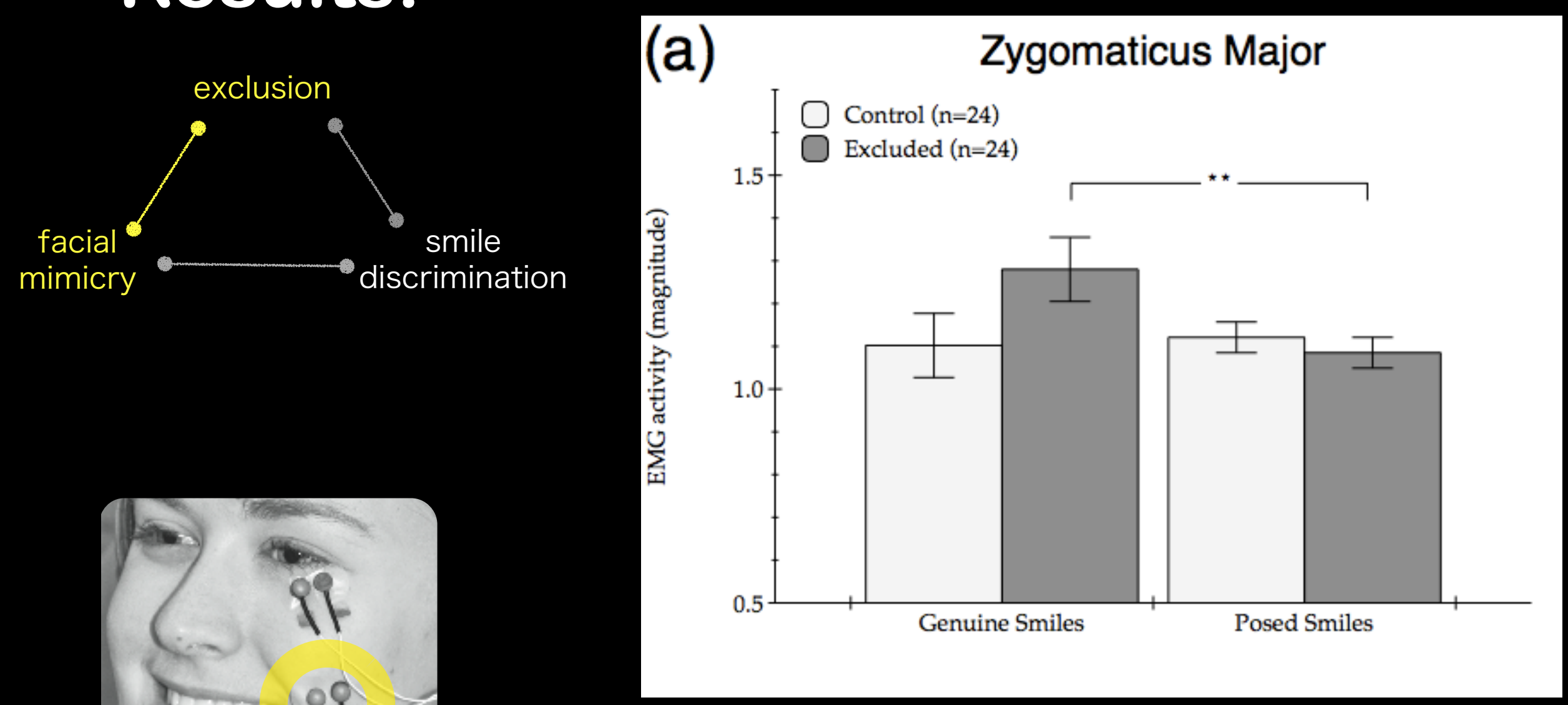

Mean EMG activity by Condition and Smile type (error bars \pm 1 SEM). (a) Pairwise comparisons revealed that only Excluded participants showed more zygomaticus activity when viewing genuine smiles compared to posed smiles $(* * p$ $=.01$ ). (b) There was no effect of exclusion on orbicularis oculi activity. 


\section{Results:}
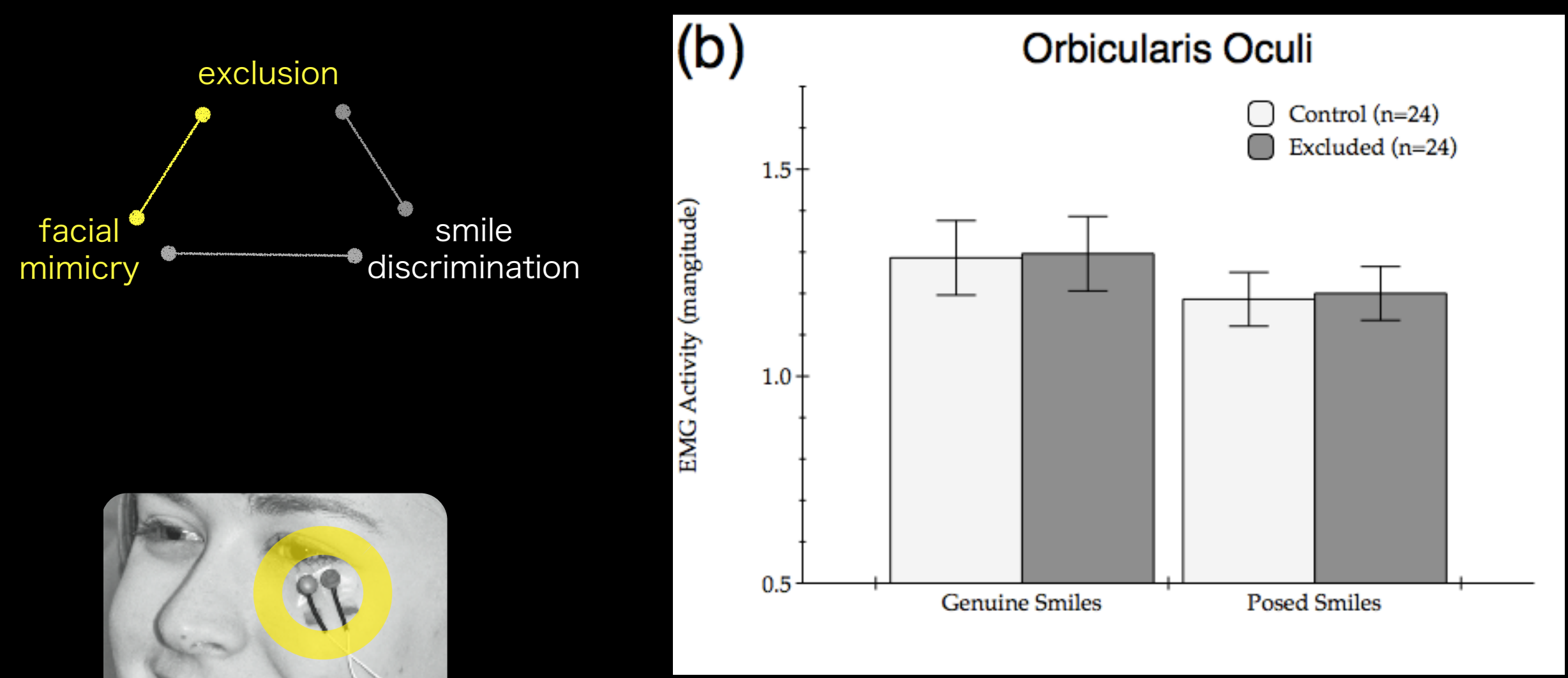

Mean EMG activity by Condition and Smile type (error bars \pm 1 SEM). (b) There was no effect of exclusion on orbicularis oculi activity. 


\section{Results:}

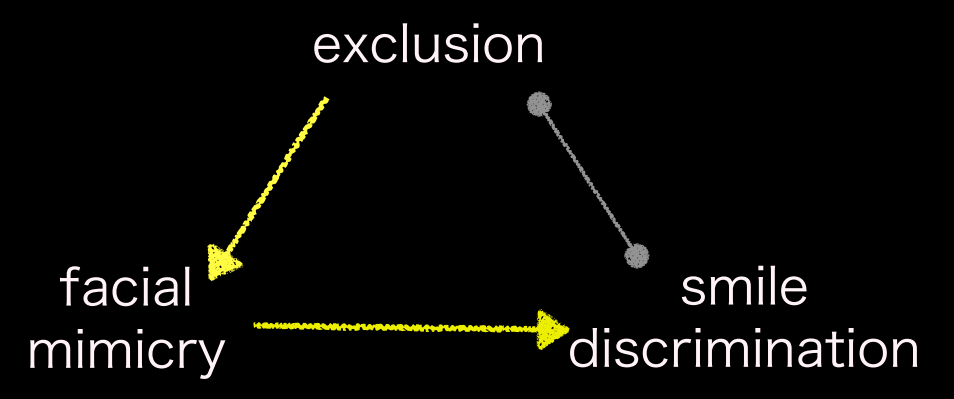

Does facial mimicry of emotional expression explain the changes in smile discrimination?

No. 
Social exclusion selectively affects reciprocation of facial gestures.

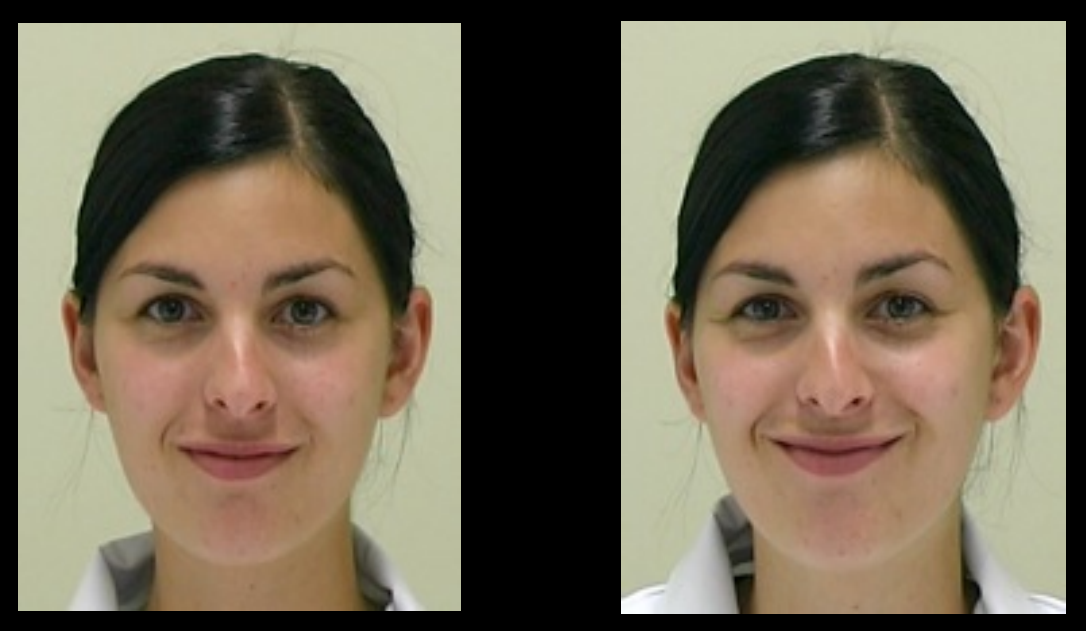

\section{conclusions}


Social exclusion selectively affects reciprocation of facial gestures.

$$
\text { why? }
$$
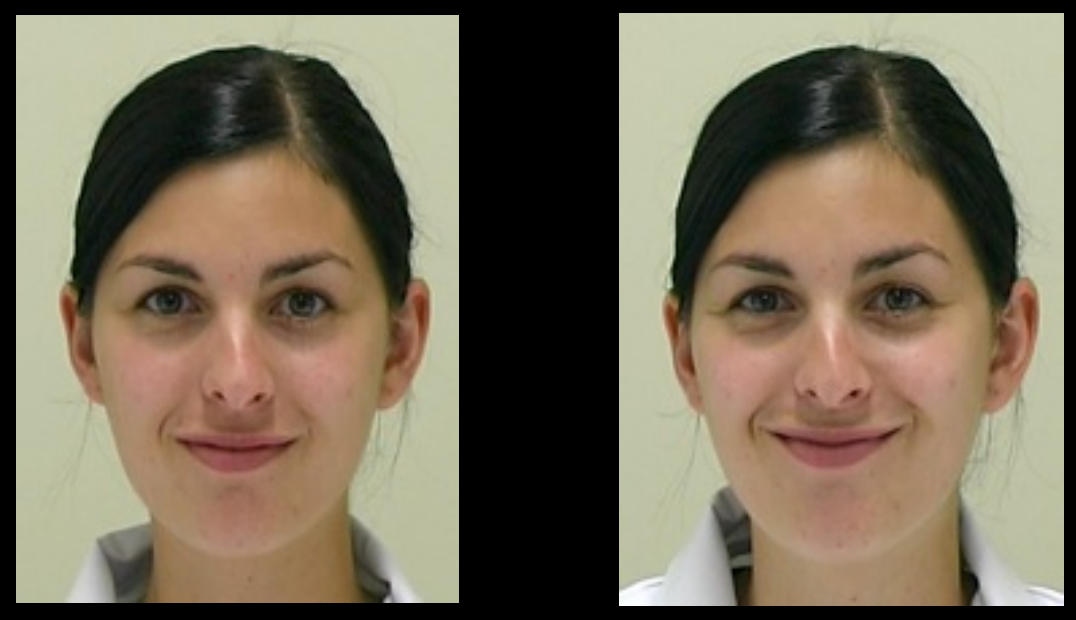

\section{conclusions}

